\title{
The responses of evapotranspiration due to changes of LUCC under seawater intrusion in a coastal region
}

\author{
Xiaoming Cao $\cdot$ Zhiqiang Gao
}

Received: 22 May 2012/Accepted: 21 January 2013/Published online: 2 February 2013

(c) Springer-Verlag Berlin Heidelberg 2013

\begin{abstract}
The paper provides a coherent pattern identification analysis of the impacts of coastal land use and land cover (LULC) on evapotranspiration (ET) under the impact of seawater intrusion. The study applied the Landsat satellite data to characterize the LULC at Laizhou Bay, Shandong Province, China. Then, the ET and heat fluxes were estimated using the surface energy balance algorithm for land model with two-time phase thermal infrared band images and regional surface parameters. This allowed for the eventual linkage of seawater intrusion to land use/cover changes (LUCC) and ET variations over time. The case study discussed in this paper carried out a coastal landscape dynamics assessment using multi-source and multi-sensor remote sensing technologies. The results are: (1) due to its distance from the sea, the vegetation index (modified soiladjusted vegetation index, MSAVI) gradually increases with the gradual increase of land use grade (Uindex); (2) there are a variety of types of relational patterns between parameters (LST, $\mathrm{G}_{\mathrm{n}}$, MSAVI, and Uindex) and ET (positive, negative, and no relationship); and (3) seawater intrusion significantly affected the spatial pattern of LUCC, which evidently affected the spatial distribution of ET. The spatial distribution pattern and change characteristics of ET were formed by double driving forces of
\end{abstract}

\footnotetext{
X. Cao

State Key Laboratory of Resources and Environmental Information Systems, Institute of Geographical Sciences and Natural Resources Research, Chinese Academy of Sciences, Beijing 100101, China

e-mail: caoxm1027@gmail.com

Z. Gao $(\bowtie)$

Yantai Institute of Coastal Zone Research, Chinese Academy of Science, Yantai 264003, China

e-mail: gaoland@gmail.com
}

seawater intrusion and LUCC under the background effects of regional climate.

Keywords Evapotranspiration - Land use and land cover . Remote sensing $\cdot$ Seawater intrusion

\section{Introduction}

The coastal zones consistently experience the strongest sealand interactions which make sustainable land use management not only challenging, but at times, nearly intangible. As economic development has rapidly accelerated over the last few decades, many environmental problems, such as overexploitation of land resources, seawater intrusion, overdraft of groundwater, coastal urban sprawl, increased aquacultural or maricultural activities, etc., have come to be recognized as driving forces behind changes in land use and land cover (LULC) patterns. The relationship between water flux and land use/cover changes (LUCC) needs to be further characterized in response to water sustainability impacts (Guan et al. 2001; Allen et al. 2005a, b; Billi and Caparrini 2006).

It is believed that with existing remote sensing images and in situ observations in support of coastal margin change detection around the world at a variety of scales, the assessment of ET variations as an alternative way of measuring system adaptive capacity could help in the understanding of LUCC, and even land remediation potential, such as re-zoning in coastal regions (Guan et al. 2001). Estimating land cover effects on ET with remote sensing has become a focal point in the realm of land use dynamics (Liu et al. 2005; Billi and Caparrini 2006; Quan et al. 2006). This, in turn, has led to the long-term study of water cycle characterization using modeling, remote sensing, and data assimilation under climate changes. 
Coastal land use dynamics is, therefore, intimately tied to concomitant response of some hydrological factors, such as ET (Andrea et al. 2001; Fohrer et al. 2001; Klöcking and Haberlandt 2002; Wegehenkel 2002; DeFries and Eshleman 2004). The relationship between water flux, land surface temperature (LST), seawater intrusion, and LUCC needs to be further characterized in the context of water sustainability. The evaluation and prediction of the hydrological consequences associated with land use dynamics at multiple scales (DeFries and Eshleman 2004) is now feasible with the aid of satellite remote sensing data and modeling capabilities. In recent decades, many scientists have studied the impacts of LUCC on water/heat fluxes (Toby and Tracy 2000; Fohrer et al. 2001; Klöcking and Haberlandt 2002; Krause 2002; DeFries and Eshleman 2004; Tracy 2004).

Various thermal data sources can together provide the synergistic capacity needed to offer real-time, scalable surface ET and soil moisture information. In Europe, Menenti and Choudhury (1993) proposed surface ET based on the surface energy balance index (SEBI). Later, the simplified surface energy balance index (S-SEBI) was used to study the interaction between radiation and energy fluxes from point to regional scale using LANDSAT-TM scene (Roerink et al. 2000). Bastiaanssen et al. (1998a, b, 2000) estimated regional ET based on the surface energy balance algorithm for land (SEBAL) model with the aid of Landsat-TM satellite images.

Estimating LUCC effects on the ET distribution with the use of remote sensing has become a focal point in the realm of land use dynamics (Baron et al. 1998; Tracy 2004; Liu et al. 2005; Billi and Caparrini 2006; Quan et al. 2006). Therefore, by incorporating remote sensing technologies, this paper aims to provide a coherent analysis of pattern changes in LULC in relation to ET variations under the impact of seawater intrusion. The authors attempted here to analyze the spatial patterns of land cover change and its effects on ET under the influence of seawater intrusion. Moreover, the goal of this study is to provide scientific support and a decision-making basis for regional land use planning, beach land resource development, and ecoenvironmental protection of coastal wetlands.

\section{Methodology}

The study area

The study area $\left(36^{\circ} 48.55^{\prime} \mathrm{N} \sim 37^{\circ} 32.82^{\prime} \mathrm{N}, 118^{\circ} 37.62^{\prime} \mathrm{E}\right.$ $\left.\sim 119^{\circ} 44.50^{\prime} \mathrm{E}\right)$ which consists of varying geologic intensities of sea-land interactions, is located at Laizhou Bay in Shandong Province, China (Fig. 1). It measures approximately $97 \mathrm{~km}$ from east to west and $79 \mathrm{~km}$ from north to south. The total study area is 486,245 hectares. Land elevation drops mildly from 30 to $2 \mathrm{~m}$ above sea level, and the length of the meandering coastal line within the study area is about $400 \mathrm{~km}$. This active floodplain was formed by the release of sediment laden water from the neighboring river channel through regional morphological and sedimentary dynamics. Shouguang City, the Hangting area of Weifang City, and most of Changyi City are situated along this coast line. The sediment distribution in the alluvial plain ranges from fine sand (close to the low water line) to the typical mud which is carried by flood currents. The climate system located close to the open ocean is a moist, warm, and temperate continental monsoon (Cao 2002).

Identification of multi-temporal changes of LULC and calculation of the land use degree index (Uindex)

After investigating the synergistic potential in regard to the use of multi-source and multi-sensor data, this study eventually applied the 4-, 3-, 2-band false color composite Landsat satellite data to characterize the LULC in the study area. With the aid of high-resolution remote sensing images collected on May 7, 1987 (Landsat-TM) and May 2, 2000 (Landsat ETM+), LULC classes were extracted using computer-aided manual interpretation (Fig. 2). First, based on the understanding of the object's spectral reflectance, structure and other information, the paper used MGE software to identify the land use types on the computer screen. Second, the boundaries of the objects were drawn and the attributions (labels) of the polygons were added to produce the digital map. Third, the vector digital maps were complied.

The Uindex was generated based on the classified LULC expressed below (Liu et al. 2005) as:

Uindex $=100 \sum_{i=1}^{n} A_{i} C_{i}$, Uindex $\in[100,400]$

where $A_{i}$ is a weighted index of land use degree at $i$-level, and $C_{i}$ is fractional land cover type at each pixel area at $i$-level.

Retrieval of the ET, land surface temperature (LST), and modified soil-adjusted vegetation index (MSAVI)

With the use of LANDSAT satellite images, the heat fluxes and ET were estimated with the SEBAL model and were calculated with the Arc/Info 9.0 Macro Language (AML) and Compaq Visual FORTRAN 6.5 mixed-language programming (Bastiaanssen et al. 1998a, b; Gao et al. 2010) (Fig. 3). The SEBAL-based computer package can be operated in a Microsoft Windows system using the ESRI GRID module as the major data format. 

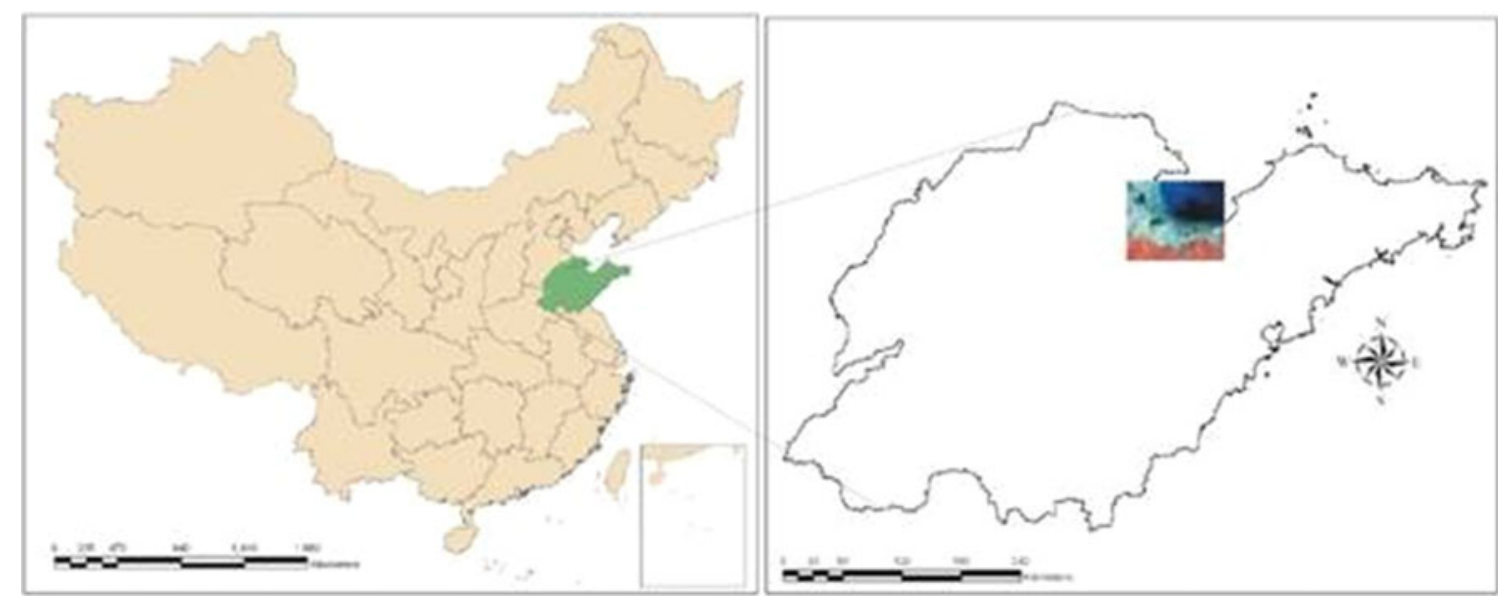

Fig. 1 The location of the study area in Shandong Province, China
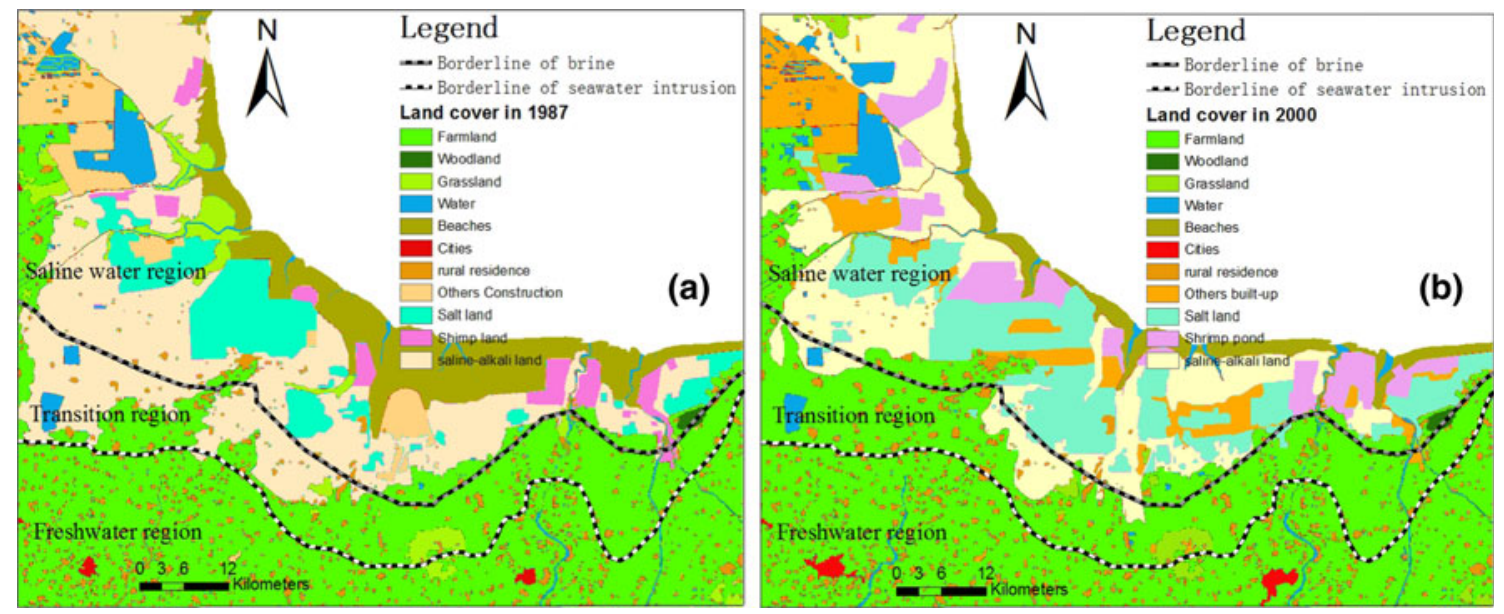

Fig. 2 The LUCC of the study area (a Land use and land cover in 1987, b Land use and land cover in 2000)
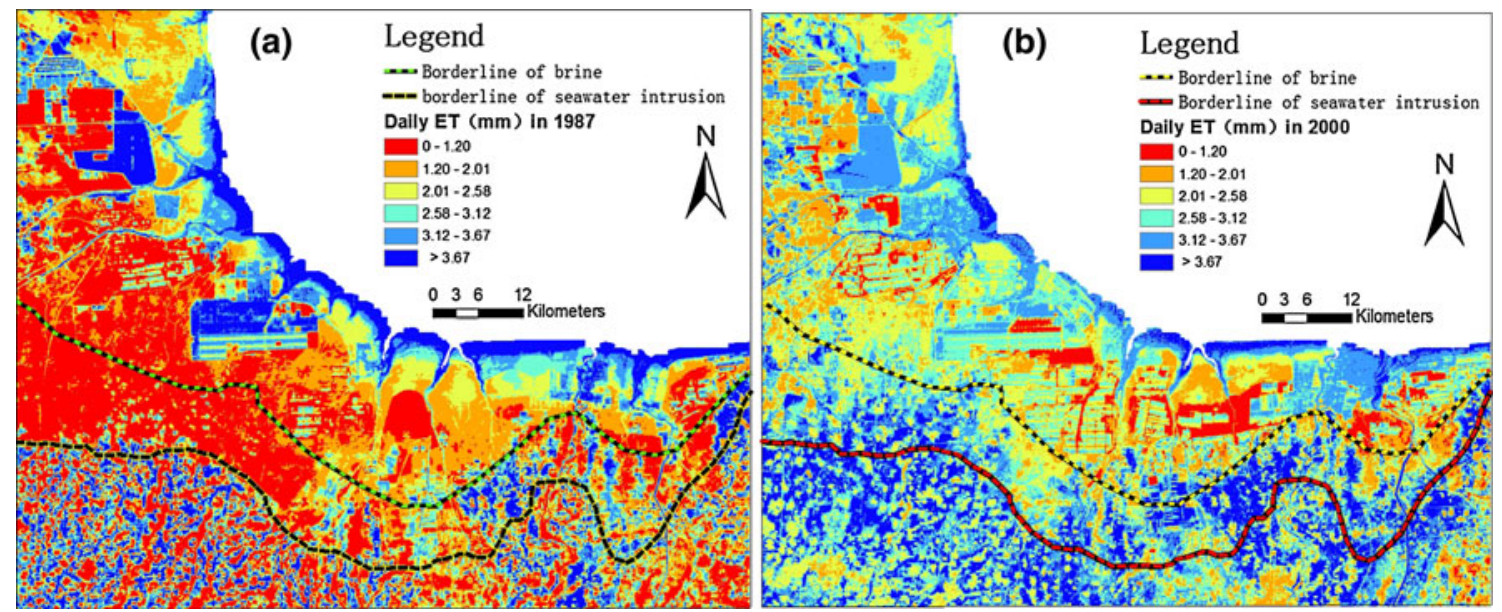

Fig. 3 The distribution maps of ET in 1987 and 2000 (a ET in 1987, b ET in 2000) 
To ease the application of the radiance transfer equation, Qin et al. (2001) derived an approximate expression for LST retrieval suitable for thermal bands of TM/ETM+ data. The LST maps were also derived based on the same algorithm developed by Qin et al. (2001).

The equation for MSAVI (Qi et al. 1994) is summarized as:

$M S A V I=\frac{1}{2} *\left[\left(2 \rho_{\text {nir }}+1\right)-\sqrt{\left(2 \rho_{\text {nir }}+1\right)^{2}-8\left(\rho_{\text {nir }}-\rho_{\text {red }}\right)}\right]$

where $\rho_{\text {red }}$ is red band $(0.63-0.69 \mu \mathrm{m})$ reflectance, and $\rho_{\text {nir }}$ is near red band $(0.76-0.90 \mu \mathrm{m})$ reflectance.

\section{Results and analysis}

The spatial pattern analysis of essential geophysical parameters (MSAVI, LST, Uindex, and $\mathrm{G}_{\mathrm{n}}$ )

Over the past two decades, seawater intrusion has become a serious environmental management issue. Over the past 10 years, field sampling campaigns have helped to clearly define the boundaries, such as the borderlines of the brine on the south coast of Laizhou Bay (Zhang and Wang 2007), and also of the seawater intrusion in 2000 (Zhang and Peng 1998) in the saline water, transition, and freshwater regions (Cao 2002; Wang et al. 2002). Figure 2a and $b$ shows that the areas north of the brine borderline are in the saline water region. The remaining areas are largely composed of fish ponds and saline-alkali land. The area south of the borderline of seawater intrusion is the freshwater region, which mostly consists of constructed land and farmland. The transition region between the borderlines of the brine and the seawater intrusion mainly consists of farmland, saline-alkali land, and sporadic rural residential areas.

The major characteristics of LUCC in the subregions are summarized as follows: (1) the saline water region accounted for $50.62 \%$ of the total area (481,928 hectares) and the changes which occurred in this region comprise as much as $79.23 \%$ of the total change area (134,940 hectares); whereas the decrease also includes beach land, saline-alkali land, and grassland, the increase includes salt land, shrimp ponds, other constructed land, and farmland. (2) The transition region accounted for $21.19 \%$ of the total area; however, within the same time period, the changes in the transition region accounted for only $17.65 \%$ of the total change area in which the decrease of saline-alkali land and the increase of farmland and rural residential areas occurred. (3) The freshwater region accounted for $28.19 \%$ of the total area. The change in this region is much smaller, accounting for $3.12 \%$ of the total change area in which the decrease of farmland and the increase of rural residential areas and cities occurred.

As shown in Figs. 4 and 5 and Table 1, this observation is evidenced by the gradient of LULC from the shoreline to the inland region, across the saline water and transition regions, and on to the freshwater region. It is shown that the $G_{n}$ value gradually decreased from the coastal region to the inland region, with the opposite gradient nearly equal to the Uindex and MSAVI changes.

In the saline water region, which is affected by seawater intrusion, saline-alkali land evolves into salt land, beach land, and shrimp ponds, with a low degree of land use. In the transition region, saline-alkali land, farmland, and rural residential units lead to a higher degree of land use. The highest degree of land use, which is driven by forces of economic development, appears in the freshwater region with an initial change from saline-alkali land into farmland, and a subsequent change into constructed land, and rural residential units. From the above analysis and Table 1, because of the influences of the seawater intrusion and the different distances from sea, there are different types of land cover, which lead to the significant changes of the surface parameters with the distance from sea (such as LST and $G_{n}$ decreased gradually, ET, MSAVI and Uindex increased gradually).

The ET change analysis in different regions between 1987 and 2000

The annual average daily ET in the saline water region was $2.07 \mathrm{~mm} /$ day in 1987 and $2.53 \mathrm{~mm} /$ day in 2000 , resulting in an increase of $0.45 \mathrm{~mm}$ (Fig. 3). In the transition region, the annual average daily ET was $1.49 \mathrm{~mm} /$ day in 1987 and $2.94 \mathrm{~mm} /$ day in 2000 , resulting in an increase of annual average daily ET of $1.45 \mathrm{~mm}$. In the freshwater region, the annual average daily ET was $2.19 \mathrm{~mm} /$ day in 1987 and $3.06 \mathrm{~mm} /$ day in 2000 , resulting in an increase of annual average daily ET of $0.87 \mathrm{~mm}$.

A comparison of the ET patterns associated with LUCC under the impact of seawater intrusion, as evidenced in Fig. 3 shows that $14.45 \%$ of the entire study area experienced a decrease of ET in the 13 year time span between 1987 and 2000. This decrease occurred primarily in the saline water region. Alternatively, $56.32 \%$ of the entire study area exhibits an increase of ET which mainly occurred within the transition and freshwater regions. The unchanged areas of ET only account for $29.3 \%$ of the entire study area. As of 2000, the annual average daily ET increased by $0.45 \mathrm{~mm} / \mathrm{day}$ in the saline water region, $1.45 \mathrm{~mm} /$ day in the transition region, and $0.87 \mathrm{~mm} /$ day in the freshwater region.

The ET variations resulting from the changes in land use over several decades are literally correlated with seawater 

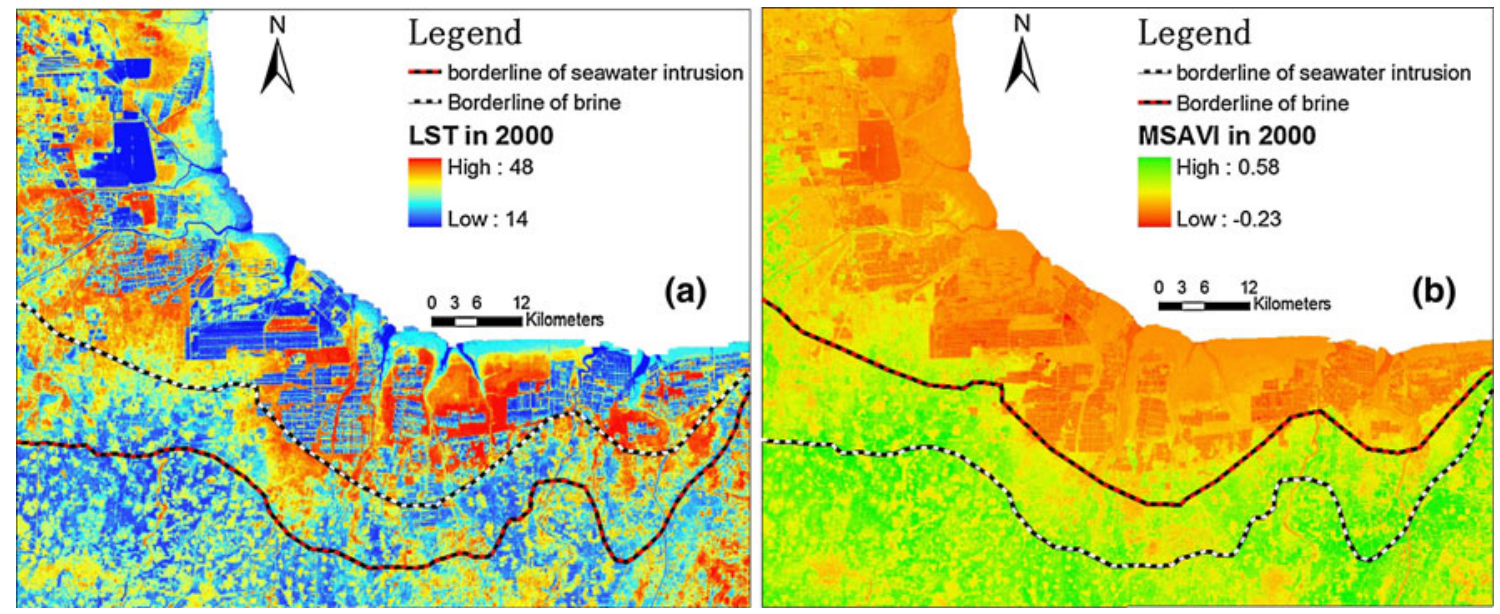

Fig. 4 The distribution maps of LST and MSAVI 2000 (a LST, b MSAVI)
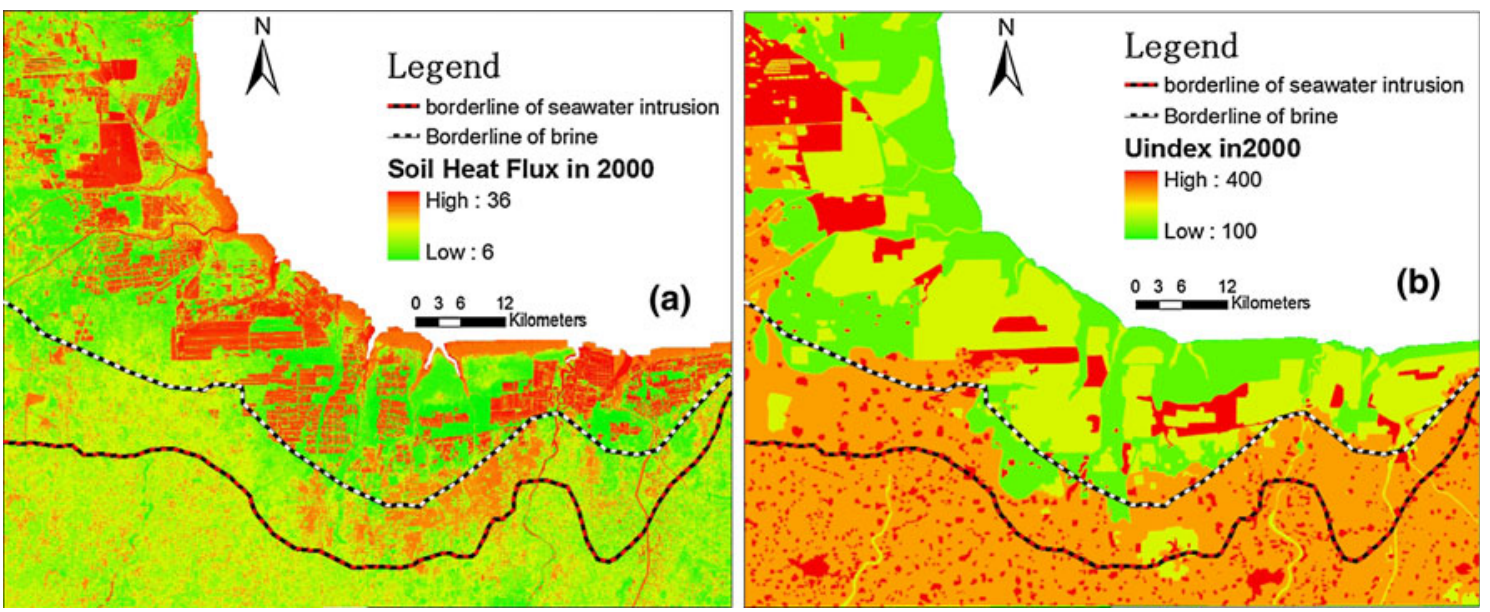

Fig. 5 The distribution maps of $G_{n}$ (soil heat flux) and Uindex in $2000\left(\mathbf{a} G_{n}\right.$, b Uindex)

Table 1 The essential geophysical parameters of different regions in 1987 and 2000

\begin{tabular}{lcccc}
\hline Regions & Saline water region & Transition region & Freshwater region & Study area \\
\hline Area $(\%)$ & 50.62 & 21.19 & 28.19 & 1900 \\
ET 1987 $(\mathrm{mm})$ & 2.03 & 1.45 & 3.02 & 1.95 \\
ET 2000 $(\mathrm{mm})$ & 2.48 & 2.89 & 29.44 & 2.72 \\
LST 1987 $\left({ }^{\circ} \mathrm{C}\right)$ & 30.00 & 32.82 & 27.76 & 30.38 \\
LST 2000 $\left({ }^{\circ} \mathrm{C}\right)$ & 29.18 & 29.05 & 15.12 & 14.66 \\
$\mathrm{G}_{\mathrm{n}}$ 1987 $\left(\mathrm{W} / \mathrm{m}^{2}\right)$ & 17.71 & 15.11 & 0.23 & 16.42 \\
$\mathrm{G}_{\mathrm{n}}$ 2000 $\left(\mathrm{W} / \mathrm{m}^{2}\right)$ & 18.14 & 14.92 & 0.24 & 0.12 \\
MSAVI 1987 & 0.05 & 0.14 & 307.49 & 0.13 \\
MSAVI 2000 & 0.04 & 0.20 & 309.85 & 225.31 \\
Uindex 1987 & 173.48 & 235.47 & 281.26 & 248.67 \\
Uindex 2000 & 201.70 & & &
\end{tabular}

intrusion on one hand, and economic development on the other. As shown in Figs. 2, 3 and 5, this observation is evidenced by the gradient of LULC from the shoreline to the inland region, across the saline water region, the transition region, and on to the freshwater region. In the saline water region, affected by the seawater instruction, 
saline-alkali land evolves into salt land, beach land, and shrimp ponds with a low degree of land use (Uindex is 173 in 1987 and 201 in 2000). In the transition region, salinealkali land, farmland, and rural residential units lead to a higher degree of land use (Uindex is 235 in 1987 and 281 in 2000). The highest degree of land use (Uindex is 307 in 1987 and 309 in 2000) driven by the forces of economic development appear in the freshwater region with an initial change from saline-alkali land into farmland, subsequent changes into constructed land, rural residential units, and eventually evolving into big cities.

The research findings clearly indicate that seawater intrusion has significantly and directly impacted LULC, and that alternatively, there has been an indirect impact on ET due to the varying levels of surface heat flux from 1987 to 2000 (ET is $1.95 \mathrm{~mm} /$ day in 1987 and $2.72 \mathrm{~mm} /$ day in 2000).

The relational patterns analysis between geophysical parameters and ET under seawater intrusion

The spatial correlations between ET and the essential geophysical parameters can be further analyzed based on remote sensing data sets; whereas the parameters of MSAVI and Uindex collectively represent the features of land cover, LST and $G_{n}$ synergistically reflect thermal conditions of land surface. The integration of ET with MSAVI, Uindex, LST, and $\mathrm{G}_{\mathrm{n}}$, with appropriate intervals, may lead to some insightful findings. Our analysis follows this philosophy choosing intervals of 0.01 for MSAVI, 1.0 for Uindex, 0.1 for LST, and 10 for $G_{n}$. Using different combinations of the 1987 and 2000 data, a plethora of correlations paired MSAVI_ET, Uindex_ET, LST_ET, and
$\mathrm{G}_{\mathrm{n} \_} \mathrm{ET}$ together (Figs. 6 and 7) to explore the embedded interdependencies pair-wise in the three regions (saline water, transition, and freshwater).

Figure 6a displays the comparative analysis between LST and ET, covering different ranges of LST in these three typical regions. In the freshwater region, there is a negative correlation between LST and ET with the correlation coefficient of 0.9 for the LST in the range of $16-19^{\circ} \mathrm{C}$; there is a negative correlation between LST and ET with the correlation coefficient of 0.99 for the LST in the range of $20-45{ }^{\circ} \mathrm{C}$. For the transition and freshwater regions, it is shown that there are some positive correlations between LST and ET when LST is $<20^{\circ} \mathrm{C}$. Alternatively, there are significant negative correlations between LST and ET when LST is $>20^{\circ} \mathrm{C}$. In the saline water region, there is a significant negative correlation in the entire temperature range between LST and ET affected by the seawater intrusion.

Figure $6 \mathrm{~b}$ displays the relational curves of $\mathrm{G}_{\mathrm{n}}$ and ET, showing the relational pattern is very similar (positive relationship) in those regions. The breakpoints appear on the curves when $G_{n}$ is near the point of $20 \mathrm{~W} / \mathrm{m}^{2}$ along the $x$ axis. When $\mathrm{G}_{\mathrm{n}}$ is $<20 \mathrm{~W} / \mathrm{m}^{2}$, the correlation coefficients are 0.95 in the saline water region, 0.99 in the transition region, and 0.96 in the freshwater region. When $G_{n}$ is $>20 \mathrm{~W} / \mathrm{m}^{2}$, the correlation coefficients are 0.99 in the saline water region, 0.98 in the transition region and 0.97 in the freshwater region. The effects of seawater intrusion and land cover change on relational patterns between $G_{n}$ and ET is insignificant.

Figure 7a shows that there are positive correlations with the correlation coefficients of 0.65 and 0.95 , when the MSAVI is in the range of $-0.07 \sim-0.01$ and
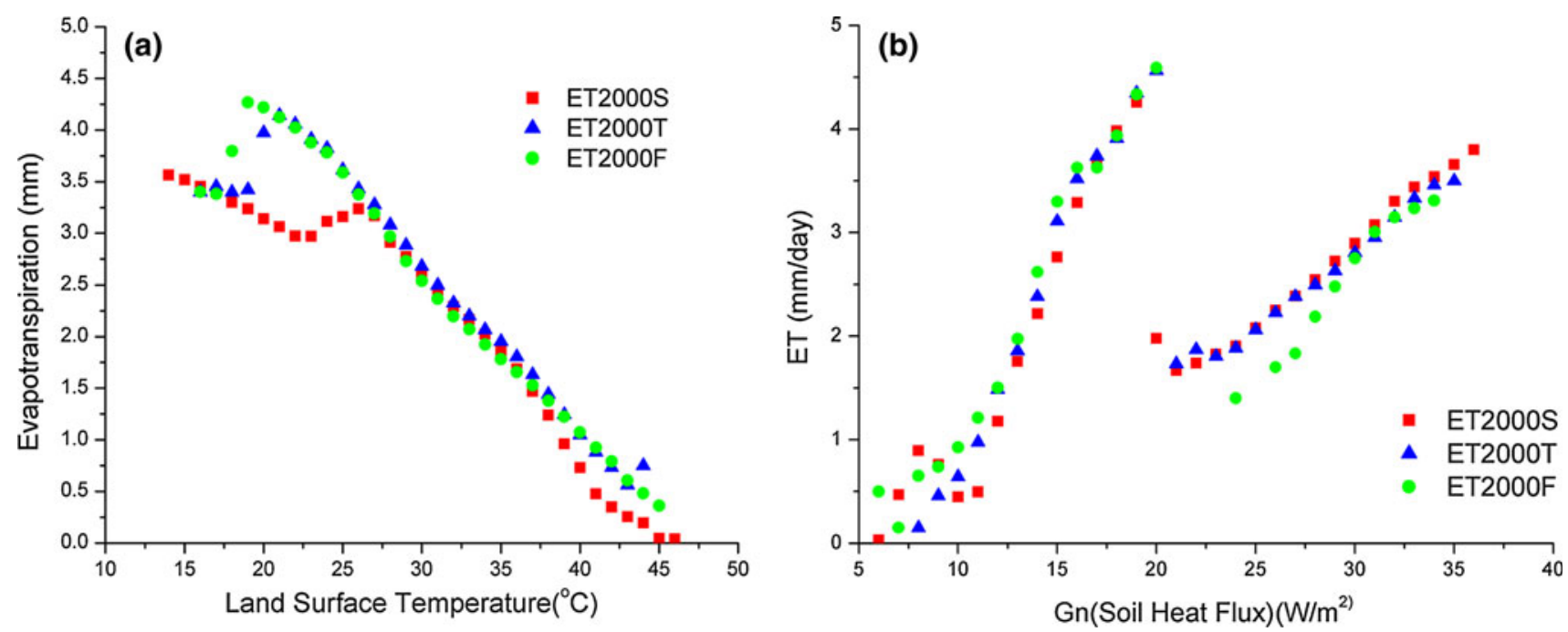

Fig. 6 The correlations between LST and ET a and between $\mathrm{G}_{\mathrm{n}}$ and ET $\mathbf{b}$ in the three typical regions ( $S$ saline water region, $T$ transition region, $F$ freshwater region) 

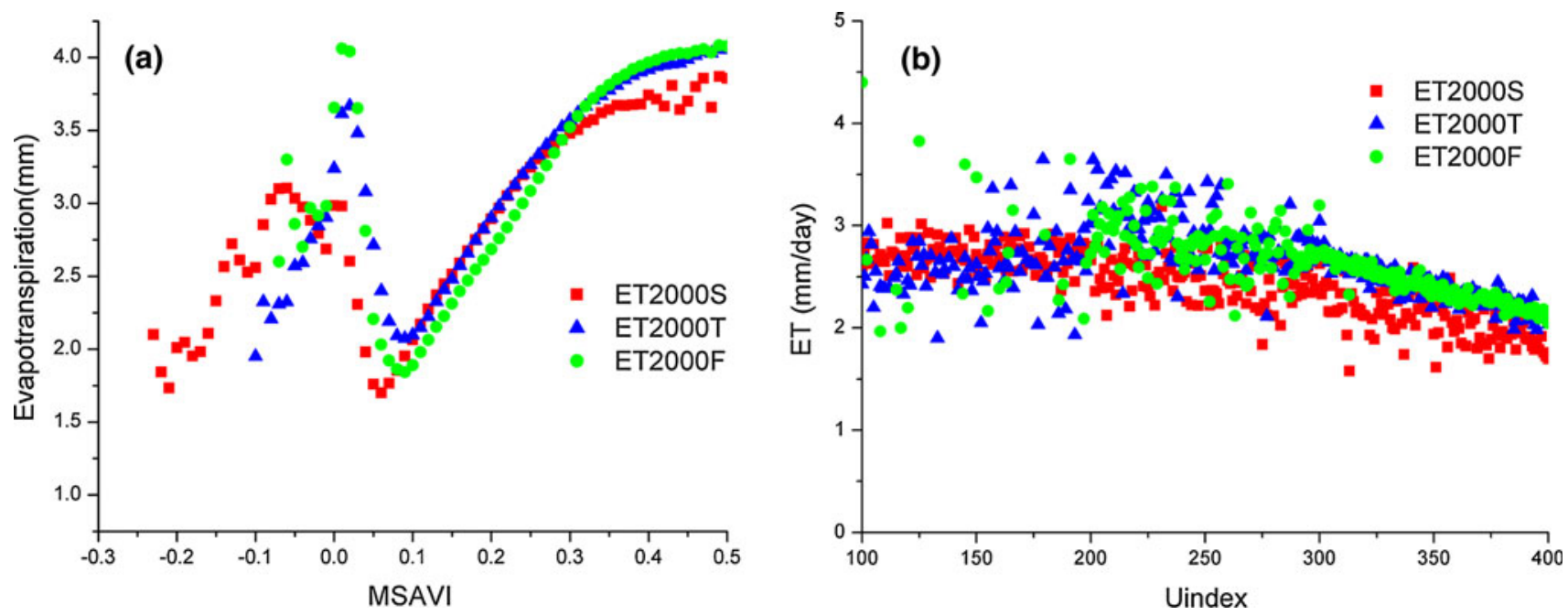

Fig. 7 Correlations between MSAVI and ET a and between Uindex and ET $\mathbf{b}$ in the three typical regions ( $S$ saline water region, $T$ transition region, $F$ freshwater region)

$0.1 \sim 0.54$. There is a negative correlation with the correlation coefficient of -0.93 , when the MSAVI is in the range of $0.02-0.09$. There is no significant relationship between MSAVI and ET, when MSAVI is $>0.54$. Thus, when MSAVI is $>0$, there is a significant negative correlation between MSAVI and ET in the study areas. When MSAVI is $<0$, under the varying levels of the seawater intrusion in all three regions, the relational patterns between MSAVI and ET are significantly different: the positive correlations between MSAVI and ET are significant in the saline water and transition regions, yet are not significant in the freshwater region.

Figure $7 \mathrm{~b}$ shows that, when the Uindex is in the range of 100-200, there is no significant correlation between Uindex and ET. When the Uindex is in the range of 201-300, there is a very weak negative correlation coefficient of -0.32 between Uindex and ET. When the Uindex is in the range of 301-400, the correlation coefficient is significant at only -0.91 between Uindex and ET. Thus, the difference in land cover type and land use degree under the effects of the seawater intrusion in the three regions resulted in the varied relational patterns between Uindex and ET. When the Uindex is $<300$ in the transition and freshwater regions, the negative correlation between Uindex and ET in the saline water region is not significant. However, when Uindex is $>300$, the negative correlations between Uindex and ET are significant.

The results show that the varying influences of seawater intrusion in the three study regions resulted in the different effects of land surface parameters (LST, $\mathrm{G}_{\mathrm{n}}$, MSAVI, and Uindex) on ET. The relational patterns between these land surface parameters and ET are significantly different under the effects of seawater intrusion and LUCC.

\section{Discussion}

At present, studies of seawater intrusion are focused on the chemical composition changes of groundwater water, instead of the influences of seawater intrusion to soil composition. In fact, seawater intrusion changes the properties of surface soil and brings serious effects to the surface ecological environment, such as the barren land, salinization, etc., which leads to significant changes on the surface environment.

In the coastal area, seawater intrusion has become a special driving force for the regional land use and land cover. The seawater intrusion significantly changes the surface land cover, while the surface land cover affects the changes of related surface parameters. Therefore, the changes of surface parameters have a significant correlation with land cover changes, and also reflect the effects of the seawater intrusion to different ecological environments.

Based on the relation between the seawater intrusion land cover (Uindex) and surface parameters (ET, $\mathrm{G}_{\mathrm{n}}, \mathrm{LST}$, MSAVI), the paper studies the influences of the seawater intrusion on land cover and the related surface parameters.

Spatially, the effects of seawater intrusion on land cover were significant, and there are obvious differences in the effects in different regions (saline water region, transition region, freshwater region). The dominant land cover of the saline water region consists of beach land, saline-alkali land, and grassland; the dominant land cover of the transition region consists of saline-alkali land and the farmland; the dominant land cover of freshwater region consists of farmland and rural residential land. Under different land cover, there are also obvious differences in the changes in surface parameter (ET, $\mathrm{G}_{\mathrm{n}}$, LST, MSAVI, Uindex) (Table 1). 

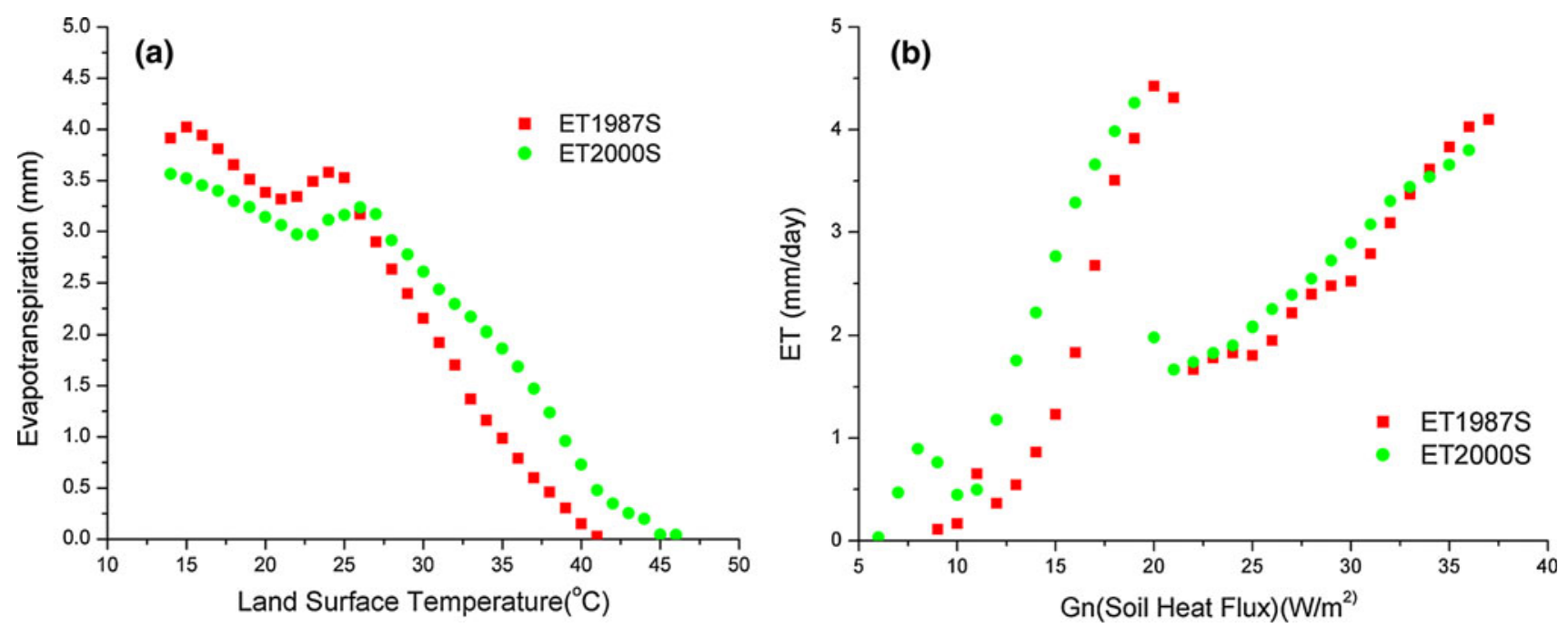

Fig. 8 The comparative correlation of LST_ET a and $\mathrm{G}_{\mathrm{n} \_}$ET $\mathbf{b}$ in 1987 and 2000 ( $S$ saline water region)

Due to the relatively slow geographic process of LUCC and saltwater intrusion, especially the slow process of the composition and structure changes resulted from saltwater intrusion, the impact of soil changes on vegetation cover has lagged. Therefore, the effects and changes of seawater intrusion on land cover and surface parameters are not too obvious with two period remote sensing data in the paper (the interval of 13 years, Figs. 8, 9).

Figures 8 and 9 display the similarities of the relational curves of LST_ET, $\mathrm{G}_{\mathrm{n}}$ ET, and MSAVI_ET in the saline water region and the curves of Uindex_ET in the freshwater region during 1987 and 2000. The changed types of land surface associated with LST, $\mathrm{G}_{\mathrm{n}}$, MSAVI, and Uindex led to the dissimilar values of ET between these 2 years. The ET in 1987 is greater than that in 2000 when MSAVI is $<0.06$ and alternatively, ET in 2000 is greater than that in
1987 when MSAVI is in the range of 0.06-0.35. The ET values in the various ranges of $G_{n}$ and Uindex in 2000 are always greater than those in 1987. It is shown that the effects of land surface parameters on ET in different years are those of quantity and size, which are not essential factors.

In summary, spatially, there are significant differences in the impacts of the seawater intrusion on different land cover, which leads to the significant changes of surface parameters. However, because of the slow geographic process of seawater intrusion, the effects of seawater intrusion on land cover and surface parameters are not significant temporally. Moreover, the research results have some uncertainties, because there the influence of seawater intrusion, LUCC on surface parameters is a very complex process.
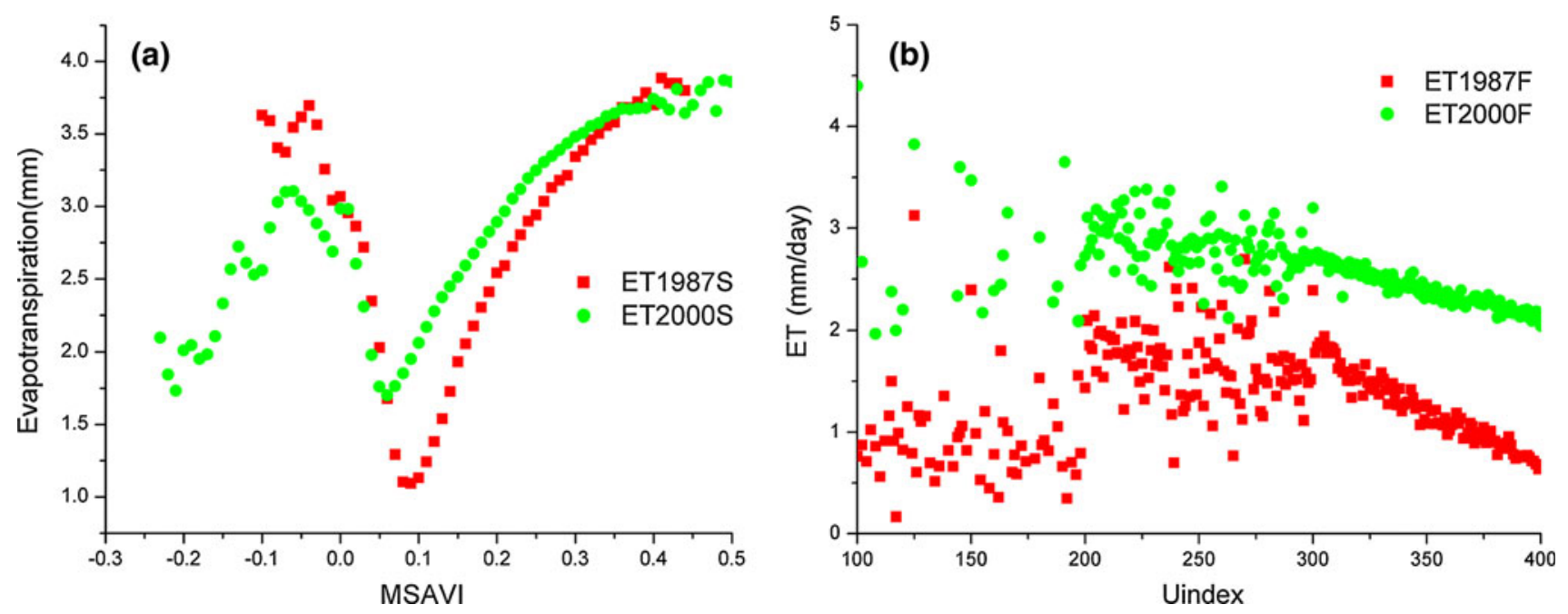

Fig. 9 The comparative correlation of MSAVI_ET a and Uindex_ET b in 1987 and 2000 ( $S$ saline water region, $F$ freshwater region) 


\section{Conclusions}

After intense examination of the synergistic potential in the use of multi-source and multi-sensor data, this study applied Landsat satellite data to characterize the LULC in the study area. With the aid of remote sensing images collected on May 7, 1987 (Landsat-TM) and May 2, 2000 (Landsat ETM+), LULC was extracted based on computer-aided manual interpretation. The corresponding ET and heat fluxes were estimated using SEBAL with two time phase thermal infrared band images and regional surface parameters. This enabled the authors to eventually link seawater intrusion to LUCC and ET variations over time.

The different levels of seawater intrusion in the three typical regions have varying effects of land surface parameters (LST, $\mathrm{G}_{\mathrm{n}}$, MSAVI, and Uindex) on ET. The relational patterns between these parameters and ET are significantly different under the effects of seawater intrusion and LUCC. The research findings from a comparison of the ET patterns associated with the land surface parameters are summarized here.

The dominant land cover of the study areas consists of farmlands, saline-alkali lands, and built-up lands. The unused land cover types of saline-alkali and beach land cover large areas. The vegetation index has gradually become greater, while the degree of land use has gradually intensified under the influence of seawater intrusion as the distance from the ocean increases.

There are positive correlations between LST and ET when LST is $<20{ }^{\circ} \mathrm{C}$, and alternatively, there are significant negative correlations when LST is $>20{ }^{\circ} \mathrm{C}$ in the transition and the freshwater regions. There is a significantly negative correlation between LST and ET in the entire temperature range, which is affected by seawater intrusion in the saline water region.

The relational pattern (positive relationship) is very similar between $G_{n}$ and ET in the three study regions. The breakpoints appear on the curves when $\mathrm{G}_{\mathrm{n}}$ is near the point of $20 \mathrm{~W} / \mathrm{m}^{2}$ along the $x$ axis. The negative correlation is significant between MSAVI and ET when MSAVI is $>0$. The relational patterns between MSAVI and ET are significantly different when MSAVI is $<0$ in the three study regions under varying levels of seawater intrusion. The dissimilar land cover types and land use degrees resulted in different relational patterns between Uindex and ET. The negative correlation between Uindex and ET is significant in the transition and the freshwater regions when Uindex is $>300$.

The research findings clearly indicate that seawater intrusion has significant and direct impacts on LULC, and yet it indirectly impacts ET due to the varying levels of surface heat flux between 1987 and 2000.
Acknowledgments This work was supported from the 52nd batches surface funded of the China Postdoctoral Science Foundation (2012M520362), National Natural Science Foundation of China (41171334 and 41071278), Talent Fund of Yantai Institute of Coastal Zone Research, Ecological Innovation \& Breeding Project (Y254021031), USDA NIFA Project (2010-34263-21075) and the Focused Deployment Project, Chinese Academy of Sciences (KZZDEW-08-02).

\section{References}

Allen RG, Tasumi M, Morse A, Trezza R (2005a) Satellite-based evapotranspiration by energy balance for western states water management. In: Proceedings of world water and environmental resources congress, vol. 5. Anchorage, Alaska, pp 15-19

Allen RG, Walter IA, Elliot RL, Howell TA (2005b) ASCE standardized reference evapotranspiration equation. American Society of Civil Engineers, Reston

Andrea W, Fohrer N, Moller D (2001) Long-term land use changes in a mesoscale watershed due to socio-economic factors-effects on landscape structures and functions. Ecol Model 140:125-140

Baron JS, Hartman MD, Kittel TGF, Band LE, Ojima DS (1998) Effects of land cover, water redistribution, and temperature on ecosystem progress in the South Platte Basin. Ecol Appl 8(4):1037-1051

Bastiaanssen WGM (2000) SEBAL-based sensible and latent heat fluxes in the irrigated Gediz Basin, Turkey. J Hydrol 229(1-2): $87-100$

Bastiaanssen WGM, Menenti M, Feddes RA (1998a) A remote sensing surface energy balance algorithm for land (SEBAL) 1 Formulation. J Hydrol 212-213:198-212

Bastiaanssen WGM, Pelgrum H, Wang J (1998b) A remote sensing surface energy balance algorithm for land (SEBAL). 2 Validation. J Hydrol 212-213:213-229

Billi P, Caparrini F (2006) Estimating land cover effects on evapotranspiration with remote sensing: a case study in Ethiopian Rift Valley. Hydrol Sci J 51:655-670

Cao J (2002) Analysis of the Cause of Seawater Intrusion in Laizhou Bay of Shandong Province. J Grad Sun Yat-Sen Uni (Nat Sci Med) 23:104-111

DeFries R, Eshleman KN (2004) Land-use change and hydrologic processes: a major focus for the future. Hydrol Process 18:21832186

Fohrer N, Haverkamp S, Eckhardt K, Frede HG (2001) Hydrologic response to land use changes on the catchment scale. Phys Chem Earth (B) 26(7-8):577-582

Gao Z, Liu C, Gao W, Chang NB (2010) A coupled remote sensing and the surface energy balance with topography algorithm (SEBTA) to estimate actual evapotranspiration over heterogeneous terrain. Hydrol Earth Syst Sci 7:4875-4924

Guan YX, Liu GH, Wang JF (2001) Saline-alkali land in the Yellow River Delta: amelioration zonation based on GIS. J Geog Sci 11:313-320

Klöcking B, Haberlandt U (2002) Impact of land use changes on water dynamics - a case study in temperate meso and macroscale river basins. Phys Chem Earth (B) 27:619-629

Krause P (2002) Quantifying the impact of land use changes on the water balance of large catchments using the J2000 model. Phys Chem Earth (B) 27:663-673

Liu J, Zhan J, Deng X (2005) Spatio-temporal patterns and driving forces of urban land expansion in China during the economic reform era. Ambio 34:450-455

Menenti M, Choudhury BJ (1993) Parametrization of land surface evapotranspiration using a location-dependent potential 
evapotranspiration and surface temperature range. Exchange processes at the land surface for a range of space and time scales. IAHS Publication 212:561-568

Qi J, Chehbouni A, Huete AR, Kerr YH, Sorooshian S (1994) A modified soil adjusted vegetation index. Remote Sens Environ 48:119-126

Qin Z, Karnieli A, Berliner P (2001) A mono-window algorithm for retrieving land surface temperature from Landsat TM data and its application to the Israel-Egypt border region. Int J Remote Sens 22(18):3719-3746

Quan B, Chen JF, Qiu HL, Romkens MJM, Yang XQ, Jiang SF, Li BC (2006) Spatial-temporal pattern and driving forces of land use changes in Xiamen. Pedosphere 16:477-488

Roerink GJ, Su Z, Menenti M (2000) S-SEBI: a simple remote sensing algorithm to estimate the surface energy balance. Phys Chem Earth (B) 25(2):147-157

Toby NC, Tracy SA (2000) The impact of land use-land cover changes due to urbanization on surface microclimate and hydrology: a satellite perspective. Global Planet Change 25:49-65

Tracy ET (2004) Effects of land cover change on the energy and water balance of the Mississippi River Basin. J Hydrometeorol 5:640-655

Wang Q, Ren Z, Sun G (2002) Research on seawater intrusion disaster in south- east coastwise area of Laizhou Bay. Marine Environ Sci 21:10-13

Wegehenkel M (2002) Estimating of the impact of land use changes using the conceptual hydrological model THESEUS - a case study. Phys Chem Earth (B) 27:631-640

Zhang ZL, Peng LM (1998) The underground water hydrochemical characteristics on sea water intruded in eastern and southern coasts of Laizhou bay. China Environ Sci 18(2):121-125

Zhang ZL, Wang L (2007) Driving Mechanism of land use/cover change in southern Laizhou Bay. Geographic Sinica 27(1): $40-45$ 